\title{
Organic Osmoregulatory Solutes in Cyanobacteria
}

\author{
By MARK A. MACKAY, ${ }^{1}$ RAYMOND S. NORTON ${ }^{2 *}$ AND \\ LESLEY J. BOROWITZKA ${ }^{3}$ \\ ${ }^{1}$ Department of Biology, University of Wollongong, Wollongong, NSW 2500, Australia \\ ${ }^{2}$ School of Biochemistry, University of New South Wales, Kensington, NSW 2033, Australia \\ ${ }^{3}$ Roche Algal Biotechnology, School of Environmental and Life Sciences, Murdoch University, \\ WA 6150, Australia
}

(Received 23 January 1984; revised 16 March 1984)

\begin{abstract}
The major organic osmoregulatory solutes of 36 cyanobacteria from a wide range of environmental sources have been examined using ${ }^{13} \mathrm{C}$ nuclear magnetic resonance spectroscopy. These strains were also examined for their salt-tolerance, and could be arranged in three salt-tolerance groups, designated freshwater, marine and hypersaline. The most salt-tolerant cyanobacteria in the hypersaline group are properly classified as moderately halophilic. Cyanobacteria from all habitats and taxonomic groups accumulated organic osmoregulatory solutes, and the chemical class of the solute correlated with the salt-tolerance and habitat of the strain. Freshwater strains accumulated simple saccharides, predominantly sucrose and trehalose; marine strains accumulated the heteroside $O-\alpha-\mathrm{D}$-glucopyranosyl- $(1 \rightarrow 2)$-glycerol, and hypersaline strains accumulated sucrose and/or trehalose together with glycine betaine or the novel solute L-glutamate betaine ( $N$-trimethyl-L-glutamate) or they accumulated glycine betaine alone. The results suggest that the presence of certain major organic osmoregulatory solutes may be useful in the numerical taxonomy of cyanobacteria, and in the identification of some ionic characteristics of the environment of origin of each isolate.
\end{abstract}

\section{INTRODUCTION}

Cyanobacteria inhabit environments which differ dramatically in their salinity. A number of studies examining the response of cyanobacteria to saline environments have dealt with the salt tolerance of freshwater and marine forms (Van Baalen, 1962; Stewart, 1964; Batterton \& Van Baalen, 1971; Stam \& Holleman, 1975, 1979; Mackay et al., 1983; Richardson et al., 1983) and with the distinction between halophilic and halotolerant cyanobacteria (Hof \& Frémy, 1933; Batterton \& Van Baalen, 1971; Brock, 1976; Yopp et al., 1978a; Golubic, 1980). Only a few studies have dealt specifically with the organic solutes accumulated by cyanobacteria adapting to salt stress.

Accumulation of organic compounds as osmoregulatory solutes in cyanobacteria was first reported by Borowitzka et al. (1980), who used natural-abundance ${ }^{13} \mathrm{C}$ nuclear magnetic resonance (NMR) spectroscopy of cells and cell extracts, to show that the major organic osmoregulatory solute in the marine isolate Synechococcus N100 was the heteroside $O$ - $\alpha$-D-glucopyranosyl-( $(1 \rightarrow 2)$-glycerol. ${ }^{13} \mathrm{C}$ NMR spectroscopy is a useful tool in the study of osmoregulation because it is non-destructive and can provide, in a single assay, information about all free organic solutes present at concentrations sufficient to contribute significantly to intracellular osmotic pressure (Norton, 1979, 1980). This technique is non-invasive and has been used with live cells (Norton et al., 1982; Hocking \& Norton, 1983).

Mackay et al. (1983) examined 28 strains of cyanobacteria isolated from a wide range of habitats. These strains were classified into three groups, freshwater, marine and salt-tolerant, on the basis of the salinity range over which they could grow. Eleven strains classified as 'marine' 
had a distinctive salinity tolerance range, tolerating at least 60 but not more than $110 \mathrm{~g} \mathrm{NaCl}^{-1} .{ }^{13} \mathrm{C} \mathrm{NMR}$ analysis showed that each of these marine strains accumulated glucosylglycerol as the major organic osmoregulatory solute, and on this basis it was suggested that this property was a useful marker of marine strains. More recently, Richardson et al. (1983) reported that Synechocystis PCC 6803, isolated from freshwater but able to grow in seawater media, accumulated glucosylglycerol in response to increasing salinity of its growth medium. In addition, Synechocystis DUN52, a halophilic species, employed glycine betaine as its major osmoticum (Mohammad et al., 1983), and the freshwater species Nostoc muscorum PCC 7119 accumulated sucrose (Blumwald \& Tel-Or, 1982). Thus, it appears that organic compounds are important osmoregulatory solutes in a large number of cyanobacteria. By contrast, a strain of Aphanothece halophytica isolated from salt-works accumulated $\mathrm{K}^{+}$as its primary response to increased external salinity, although pools of carbohydrates, polyols and amino-nitrogen also increased at high salinity (Miller et al., 1976; Yopp et al., 1978a,b).

Although Mackay et al. (1983) found glucosylglycerol only in strains classified as marine, the ${ }^{13} \mathrm{C}$ NMR spectra revealed that all strains, marine and non-marine, accumulated organic osmoregulatory solutes of some kind. In this paper we describe the identification of these solutes in the 28 strains examined previously (Mackay $e t$ al., 1983), as well as in additional freshwater and highly salt-tolerant (hypersaline) strains. Our results show that not only do all these cyanobacteria accumulate organic osmoregulatory solutes, but there is a close correlation between the major solutes accumulated and the salinity tolerance of each strain.

\section{METHODS}

Salinity tolerance range of cyanobacteria. The upper limits of $\mathrm{NaCl}$ tolerated for growth by some strains were reported by Mackay et al. (1983). Three liquid media were used to test the salinity tolerance range of all strains : a freshwater medium, a marine medium containing some natural seawater and a medium with an artificial seawater base. All strains were tested at $23 \pm 3^{\circ} \mathrm{C}$ at $\mathrm{pH} 7.5$ in media which contained, in addition to a mineral salt base, the nitrogen, phosphorus, iron, EDTA and trace elements of BG-11 (Stanier et al., 1971) plus $1.68 \mathrm{~g} \mathrm{NaHCO}_{3}$ and $20 \mu \mathrm{g}$ vitamin $\mathrm{B}_{12} \mathrm{I}^{-1}$.

The freshwater medium used was $\mathrm{BG}-11$, which has a mineral salt base of $\left(1^{-1}\right) 0.075 \mathrm{~g} \mathrm{MgSO}_{4} .7 \mathrm{H}_{2} \mathrm{O}$ plus $0.36 \mathrm{~g} \mathrm{CaCl}_{2} .2 \mathrm{H}_{2} \mathrm{O}$. One marine medium used, medium $\mathrm{M}$, contained some natural seawater because many marine strains only grew well in its presence. It was also important to maintain a uniform level of $\mathrm{Mg}^{2+}, \mathrm{Ca}^{2+}$, and $\mathrm{K}^{+}$throughout the whole salinity range tested (see Discussion). A mineral-salt-enriched seawater stock solution was made which, after addition of the required $\mathrm{NaCl}$ and nutrients, could be adjusted to a standard volume. The mineral salt base of medium $\mathrm{M}$ contained: $100 \mathrm{ml}$ activated-charcoal-filtered seawater, $10 \cdot 17 \mathrm{~g} \mathrm{MgCl}_{2} .6 \mathrm{H}_{2} \mathrm{O}$, $1.47 \mathrm{~g} \mathrm{CaCl}_{2} \cdot 2 \mathrm{H}_{2} \mathrm{O}$ and $0.75 \mathrm{~g} \mathrm{KCl}$, which on dilution to 11 gave seawater (ZoBell, 1963) concentrations of $\mathrm{Mg}^{2+}$, $\mathrm{Ca}^{2+}$ and $\mathrm{K}^{+}$, but only $1 / 10$ seawater-strength $\mathrm{NaCl}$. Some hypersaline strains, which had been isolated on artificial media with a salt base resembling the composition of seawater, were tested using the following mineral salt base $\left(1^{-1}\right): 6 \mathrm{~g} \mathrm{MgCl}_{2} .6 \mathrm{H}_{2} \mathrm{O}, 5 \mathrm{~g} \mathrm{MgSO}_{4} .7 \mathrm{H}_{2} \mathrm{O}, 1.5 \mathrm{~g} \mathrm{CaCl}_{2} .2 \mathrm{H}_{2} \mathrm{O}$ and $1.0 \mathrm{~g} \mathrm{KCl}$.

All cultures from freshwater or marine sources and some from hypersaline sources were first tested in BG-11 and in medium $\mathrm{M}$, both with $15 \mathrm{~g}$ added $\mathrm{NaCl}^{-1}$ to determine the medium base in which they grew best. Of those strains isolated from seawater or hypersaline sources, many failed to grow in BG-11 with or without added $\mathrm{NaCl}$ and the remainder usually grew better in medium $\mathrm{M}$ with $15 \mathrm{~g} \mathrm{NaCl}^{-1}$. Among those strains isolated from a freshwater source or routinely grown in freshwater media by other culture collections, almost all showed better growth in medium with a freshwater base. Exceptions were Synechococcus N111 and Synechocystis N106, which grew slightly better in medium $\mathrm{M}$ with $15 \mathrm{~g} \mathrm{NaCl}^{-1}$.

Strains were then examined using the mineral salt base in which they grew best: strains N101-105, N109-110, N115-117, N158, 372 and 419 in BG-11; strains N106-108, N111-114, N142, N157, N161, N163, N166-167, N181-182 and N201 in medium M. Strains N100, 351-353, 355, 358, 361, 439 and 7418 (PCC 7418) were examined using the artificial seawater mineral salt base. Salinity was adjusted by increasing the concentration of $\mathrm{NaCl}$ in the medium, using increments of 5-10 $\mathrm{g}^{-1}$ for strains tested in BG-11, and of $10-20 \mathrm{~g} \mathrm{l}^{-1}$ for all other strains. No strain was tested at more than $150-160 \mathrm{~g} \mathrm{NaCl}^{-1}$.

Most strains were tested at several photon flux densities between 7 and $53 \mu \mathrm{E} \mathrm{m} \mathrm{m}^{-2} \mathrm{~s}^{-1}(0 \cdot 45-4 \cdot 00 \mathrm{klx})$, as measured with a $\mathrm{Li}$-Cor model 185-A light meter with quantum and photometric sensors. Inocula were in BG-11, medium $\mathrm{M}$ with 20,40 or $60 \mathrm{~g} \mathrm{NaCl} 1^{-1}$ or artificial seawater medium with $60 \mathrm{~g} \mathrm{NaCl}^{-1}$. Stationary phase cells were used as inocula in most experiments. Cultures which showed an increase in cell mass and colour were scored as growing, those which lost all colour and showed cell decay were scored as not growing. To determine the approximate $\mathrm{NaCl}$ concentration required to support growth of marine and halotolerant cyanobacteria, some 
strains were tested for their ability to grow in medium $\mathrm{M}$ with only low concentrations of $\mathrm{NaCl}(0-22 \mathrm{~g}$ added $\mathrm{NaCl} 1^{-1}$ ).

Growth and salt-stressing of cyanobacteria. Growth, salt-stressing and assay of the following strains from the Australian Collection of Marine Microorganisms (ACMM) has been described (Mackay et al., 1983): N100N117, N142, N157, N158, N161, N163, N166, N167, N181, N182, N201. Four strains (N103, N109, N116 and N117) were also regrown, salt-stressed and assayed at $0,5,10$ and $15 \mathrm{~g} \mathrm{NaCl}^{-1}$. Scytonema 419 (PCC 7110) was grown and extracted as in Mackay et al. (1983). The remaining strains were not salt-stressed for $2 \mathrm{~d}$, but were grown separately in their low and high $\mathrm{NaCl}$ media. Freshwater thermophile LPP 372 [Phormidium laminosum strain OH-1-p of Castenholtz (1970)] was grown at $45^{\circ} \mathrm{C}$ in medium D of Castenholtz (1970) with or without $15 \mathrm{~g}$ $\mathrm{NaCl} \mathrm{1}^{-1}$. Synechocystis 444 was grown at $34^{\circ} \mathrm{C}$ in $\mathrm{BG}-11$ with $15 \mathrm{~g} \mathrm{NaCl}^{-1}$.

A small collection of hypersaline strains, Synechococcus 352, 353, 355, 358, 361 and Spirulina 439, were grown in artificial seawater media with $60 \mathrm{~g} \mathrm{NaCl}^{-1}$ and with $90 \mathrm{~g} \mathrm{NaCl}^{-1}$. Synechococcus 7418 and 351 were grown only at $60 \mathrm{~g} \mathrm{NaCl}^{-1}$. The artificial seawater medium contained, in addition to $\mathrm{NaCl}$, the following $\left(1^{-1}\right): 6 \mathrm{~g}$ $\mathrm{MgCl}_{2} .6 \mathrm{H}_{2} \mathrm{O}, 5 \mathrm{~g} \mathrm{MgSO}_{4} .7 \mathrm{H}_{2} \mathrm{O}, 1.5 \mathrm{~g} \mathrm{CaCl}_{2} .2 \mathrm{H}_{2} \mathrm{O}, 1 \mathrm{~g} \mathrm{KCl}, 25 \mathrm{mg} \mathrm{Ca}(\mathrm{Na})_{2}$ EDTA, $1.5 \mathrm{~g} \mathrm{NaNO}_{3}, 4 \mathrm{~g}$ glycylglycine, $1 \mathrm{ml} \mathrm{A-5}$ trace elements (Stanier et al., 1971) and $3 \mathrm{ml} 5 \mathrm{M}-\mathrm{NaOH}$. After autoclaving, the following filtersterilized stock solutions were added $\left(1^{-1}\right): 1 \mathrm{ml} \mathrm{K}_{2} \mathrm{HPO}_{4}\left(30 \mathrm{mg} \mathrm{ml}{ }^{-1}\right), 1 \mathrm{ml}$ ammonium ferric citrate plus citric acid (6 mg ml-1 each), $20 \mathrm{ml} \mathrm{NaHCO} 3\left(84 \mathrm{mg} \mathrm{ml}^{-1}\right)$ and $0.2 \mathrm{ml}$ vitamin $\mathrm{B}_{12}\left(100 \mu \mathrm{g} \mathrm{ml}^{-1}\right)$.

The completed media were at $\mathrm{pH} 7.6$ at $38^{\circ} \mathrm{C}$. These hypersaline strains were grown at $37 \pm 0.5^{\circ} \mathrm{C}$ under constant light of $1.8-2.3 \mathrm{klx}$ in 500 or $1000 \mathrm{ml}$ conical flasks with stirring. When cultures reached a cell density of $1-$ $1.5 \mathrm{~g}^{-1}$, they were used as a $10 \%(\mathrm{v} / \mathrm{v})$ inoculum for 5 or 101 cultures in large glass carboys. Large cultures were grown at $38 \pm 1{ }^{\circ} \mathrm{C}$, with initial incident light of $18-20 \mathrm{klx}$ which was increased to $30 \mathrm{klx}$ as cultures became dense. When cell density reached about $1 \mathrm{~g}^{-1}$, another $20 \mathrm{ml} \mathrm{NaHCO}{ }_{3} \mathrm{1}^{-1}$ was added. Large cultures were harvested in late exponential growth phase at a cell density of $1 \cdot 5-2 \mathrm{~g} \mathrm{l}^{-1}$.

All strains, except Spirulina 439 , were harvested at room temperature $\left(22-23^{\circ} \mathrm{C}\right)$ using continuous flow centrifugation, followed immediately by centrifugation at $20800 \mathrm{~g}$ for $15 \mathrm{~min}$ at $0^{\circ} \mathrm{C}$. Spirulina 439 was harvested by pouring through six layers of gauze. The hypersaline strains were extracted by freezing and thawing twice, washing once with distilled water and repeating this sequence until the supernatant was no longer blue. The supernatant was then freeze-dried.

${ }^{13} \mathrm{C} N M R$ spectroscopy. Natural-abundance ${ }^{13} \mathrm{C}$ NMR spectra were recorded at $15.04 \mathrm{MHz}$ on a Jeol FX-60 spectrometer, or at $25.05 \mathrm{MHz}$ on a Jeol FX-100 Q spectrometer, each operating in the pulsed Fourier transform mode. Spinning sample tubes of $10 \mathrm{~mm}$ outside diameter were used. At $15.04 \mathrm{MHz}$, which was used for most of the analyses, typical spectral acquisition parameters were: $4000 \mathrm{~Hz}$ spectral band width; 8192 time-domain addresses; $15 \mu \mathrm{s}\left(60^{\circ}\right)$ radio-frequency pulses; $1.6 \mathrm{~s}$ pulse recycle time; and $1500-100000$ scans depending on the solute concentration in the cell extract. Noise-modulated, on-resonance proton decoupling was employed in all cases.

Solutes were identified by comparisons of chemicals shifts with literature values for amino acids and sugars (Rosenthal \& Fendler, 1976; Hocking \& Norton, 1983), $O$ - $\alpha$-D-glucopyranosyl-(1 $\rightarrow 2$ )-glycerol (Norton et al., 1982) and glycine betaine (Norton, 1979), each identification being confirmed by addition of the authentic compound. The novel solute L-glutamate betaine was identified as described in Results. Chemical shifts are expressed in parts per million downfield from tetramethylsilane. A trace of dioxane (at 67.8 p.p.m. from external tetramethylsilane) was used as an internal standard where necessary.

Quantification was based on the dry weight of the pellet obtained by centrifugation of the disrupted cells. This was preferred to the use of supernatant dry weights, which varied widely as a result of changes in the levels of low molecular weight organic solutes, salts and water-soluble polysaccharides.

\section{RESULTS}

\section{Salinity tolerance range}

The upper and lower limits of $\mathrm{NaCl}$ tolerated for growth by 33 strains of cyanobacteria are presented in Fig. 1. Although there appeared to be some minor discontinuities at 45-60, 110-130 and $135-150 \mathrm{~g} \mathrm{NaCl}^{-1}$, the strains displayed a continuum of increasing salinity tolerance from $<5$ to $>150 \mathrm{~g} \mathrm{NaCl}^{-1}$. All strains isolated from a saline source grew in medium containing seawater concentrations of $\mathrm{Mg}^{2+}, \mathrm{Ca}^{2+}$ and $\mathrm{K}^{+}$with a total of $22 \mathrm{~g} \mathrm{NaCl}^{-1}$ and in medium MN of Waterbury \& Stanier (1978), which contains $\frac{3}{4}$ strength natural seawater as its mineral salt base.

All those strains which displayed an absolute growth requirement for $\mathrm{NaCl}$ had this requirement fulfilled by $\leqslant 22 \mathrm{~g} \mathrm{NaCl}^{-1}$. This relatively low concentration of $\mathrm{NaCl}$ required for growth by any strain means that as the maximum salinity tolerated for growth increases, strains 


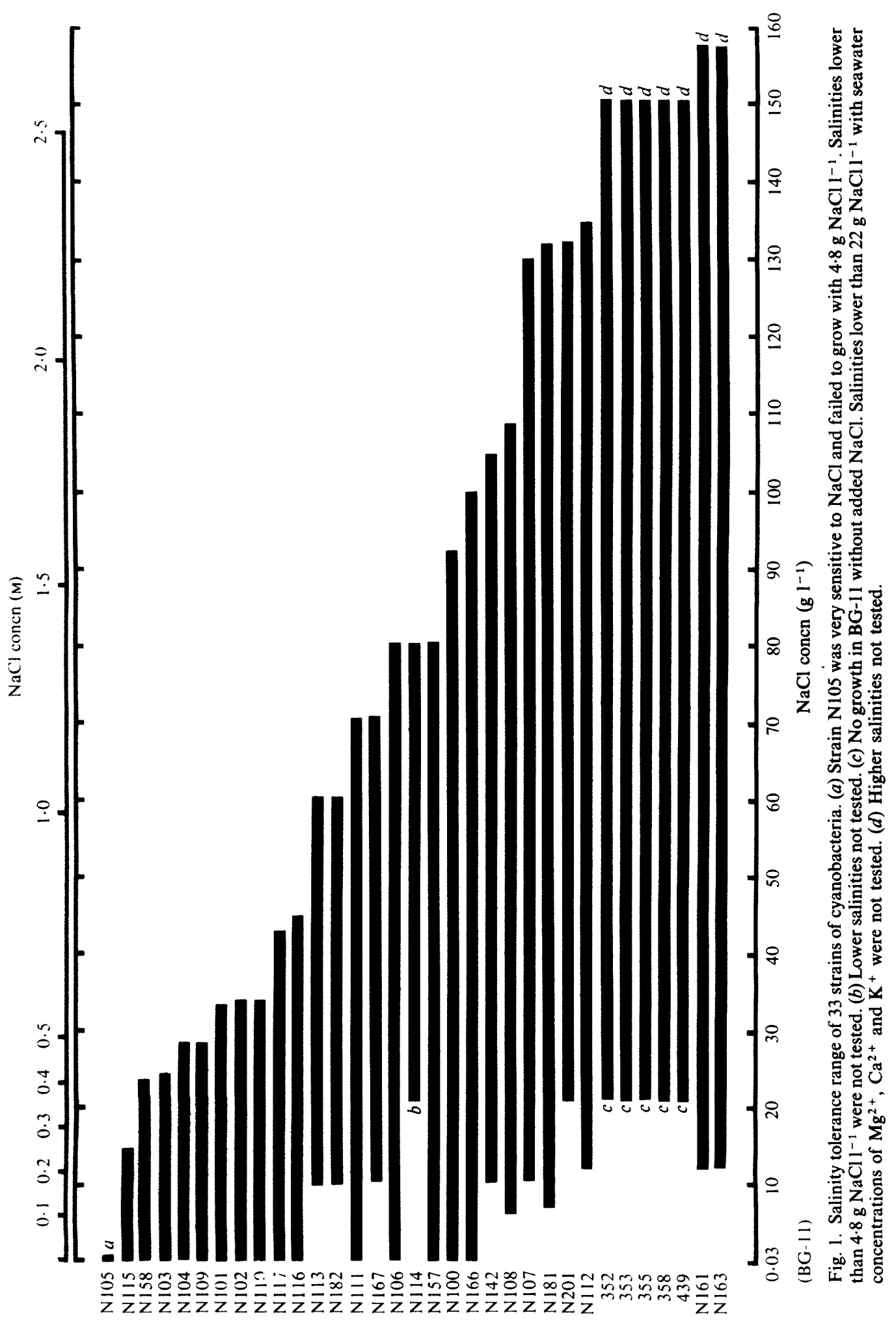


(a) Synechocystis N110

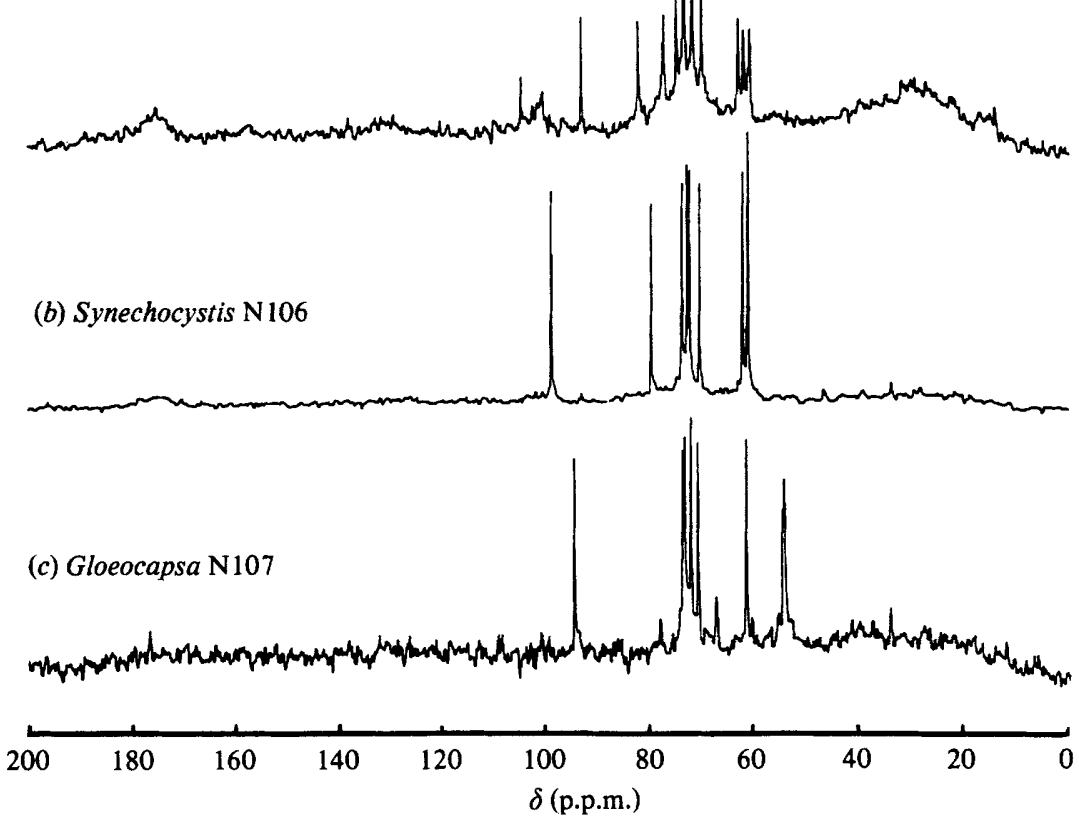

Fig. 2. Natural-abundance ${ }^{13} \mathrm{C}$ NMR spectra of aqueous extracts of cyanobacteria. Spectra were recorded at $15.04 \mathrm{MHz}$ with $60^{\circ}$ radio-frequency pulses applied in $1.6 \mathrm{~s}$ intervals and processed with $1 \cdot 1 \mathrm{~Hz}$ exponential broadening. (a) Synechocystis N110 grown in BG-11 medium with $15 \mathrm{~g}$ added $\mathrm{NaCl}$ $1^{-1} ; 0.1 \mathrm{~g}$ dry weight extract $\mathrm{ml}^{-1}, 40000$ scans. (b) Synechocystis N106 grown in medium $f$; $0.13 \mathrm{~g} \mathrm{ml}^{-1}$, 10000 scans. (c) Gloeocapsa $\mathrm{N} 107$ grown in medium $f+2.4 \mathrm{~g}$ added $\mathrm{NaCl}^{-1}$; $0 \cdot 16 \mathrm{~g} \mathrm{ml}^{-1}, 60000$ scans.

also tolerate a wider range of $\mathrm{NaCl}$ concentrations. The majority of cyanobacteria tested were euryhaline (Fig. 1). The most euryhaline strain tested tolerated from 12 to $\geqslant 158 \mathrm{~g}(0.2$ to $\geqslant 2.6 \mathrm{M}) \mathrm{NaCl}^{-1}$.

Growth of strains at the lower limit of their salinity tolerance was usually slow, although strains able to grow in the fresh water medium BG-11 grew well without any added $\mathrm{NaCl}$. Figure 1 shows the concentration of $\mathrm{NaCl}$ tolerated for growth and does not attempt to indicate the concentration of $\mathrm{NaCl}$ at which strains grew optimally.

\section{Identification of major organic osmoregulatory solutes by ${ }^{13} \mathrm{C} N M R$ spectroscopy}

Figure 2 shows natural-abundance ${ }^{13} \mathrm{C}$ NMR spectra of cell extracts of the cyanobacteria Synechocystis N110, a typical freshwater strain, Synechocystis N106, a marine strain, and Gloeocapsa N107, a hypersaline strain. The spectra were run under conditions which ensured that the peak heights (or intensities) accurately reflected the molar concentrations of the various solutes in the extracts. As all low molecular weight solutes yield sharp lines in these spectra, the relative heights (or intensities) of their resonances reflect their relative molar concentration in the cell cytoplasm. ${ }^{13} \mathrm{C}$ NMR therefore provides a simple indication of which organic solutes are significant in the maintenance of cell water activity. Furthermore, each solute of interest displayed two or more well-resolved ${ }^{13} \mathrm{C}$ resonances, which provided a useful check on quantification. Solutes were identified as being involved in osmoregulation when their concentrations increased in response to increased salinity in the medium.

The spectrum in Fig. 2(a) is typical of the many freshwater strains. The dominant osmoregulatory solute for this strain is sucrose, its 12 carbons giving rise to 10 single-carbon resonances and one two-carbon resonance. The furthest downfield peak, near 105 p.p.m., has a lower intensity than those from the other 11 carbons, as it arises from a quaternary carbon and is therefore partly saturated (Norton, 1980). Because of this, it was not used for quantification. The 

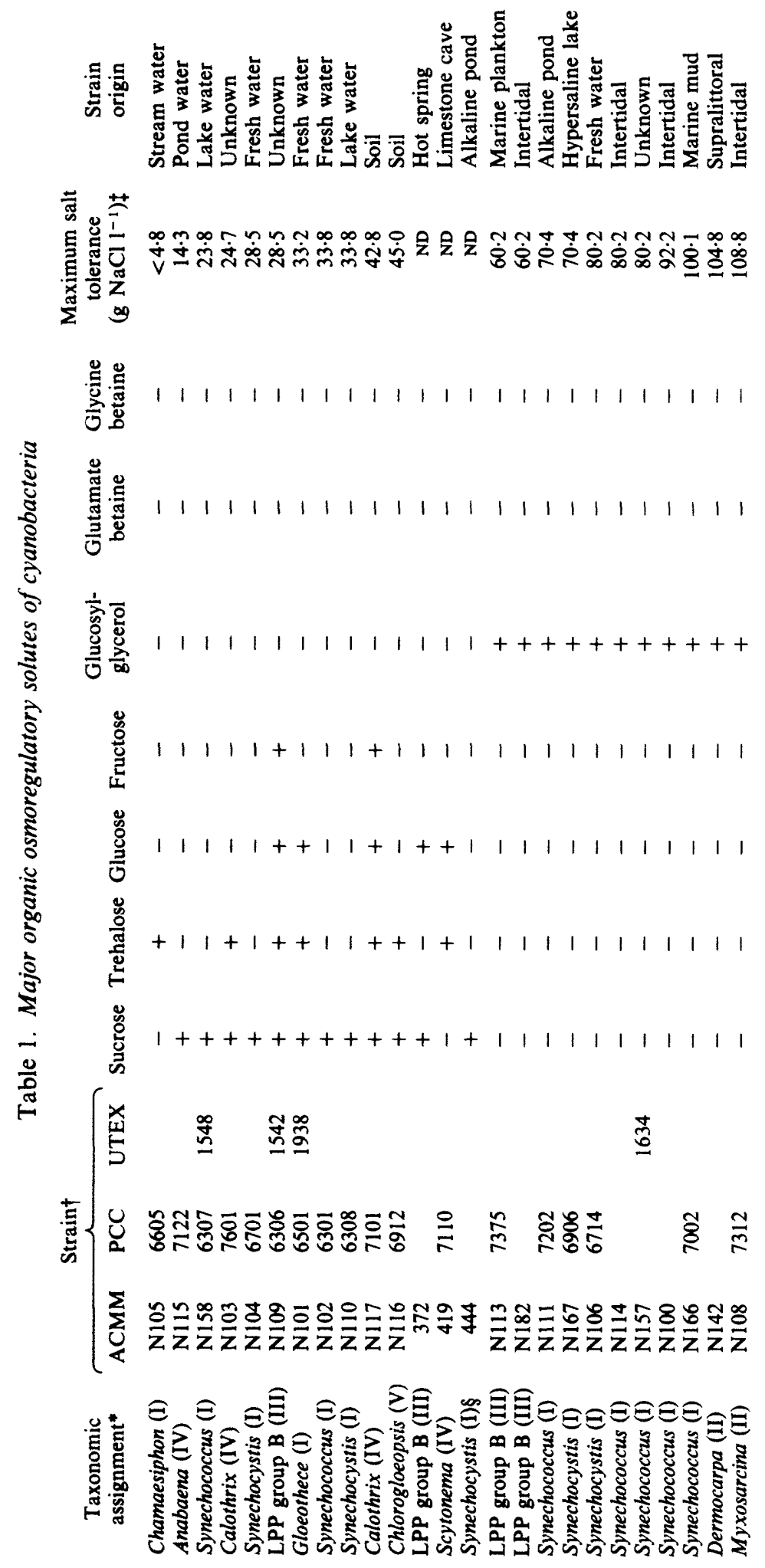


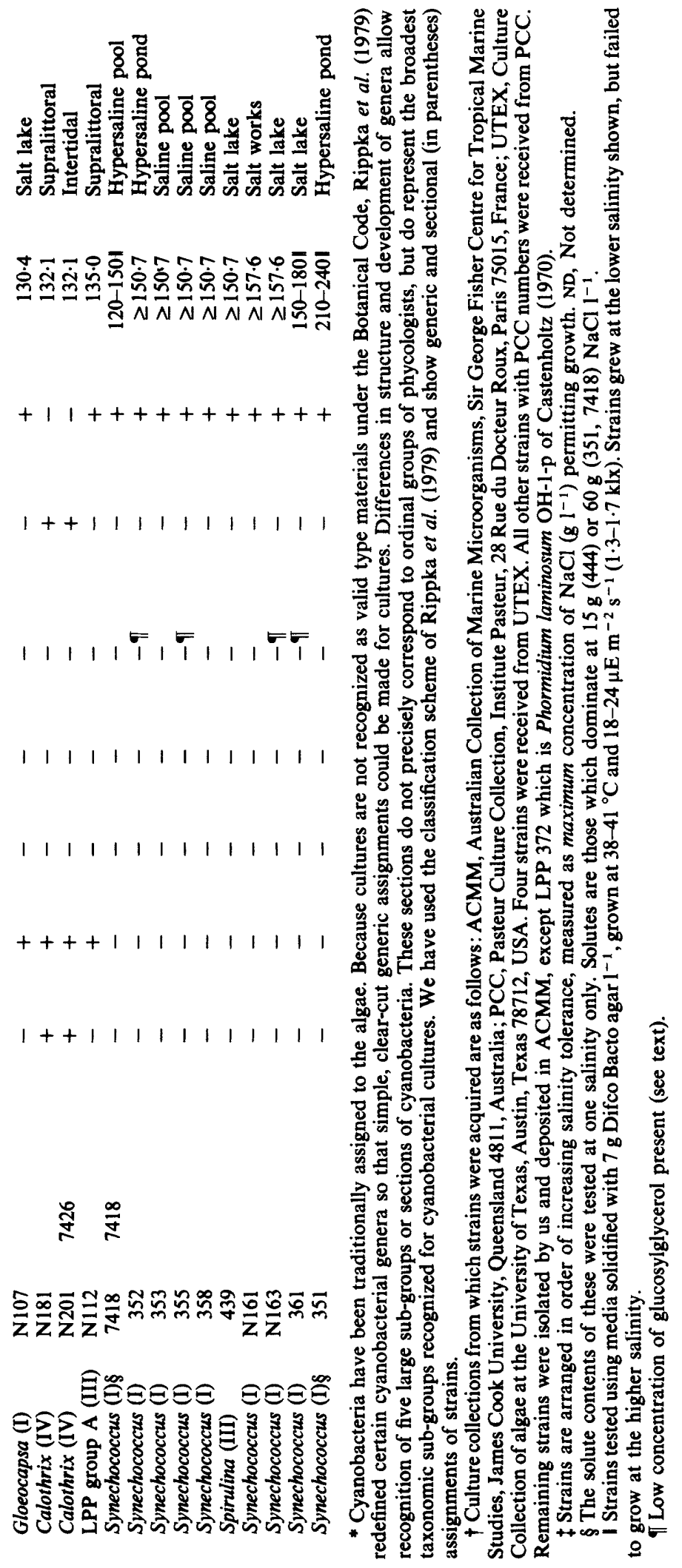


spectrum also displays broad features due to proteins and polysaccharides in the extracts. Indeed, resonances from a glucose-based polysaccharide were present in spectra of most freshwater species.

The other major osmoregulatory solute found in freshwater species was the symmetrical disaccharide trehalose. Glucose and fructose were observed in spectra of a number of strains, but only in five (N101, N109, N117, 372 and 419) did the concentrations of one or both of them increase with increased salinity in the medium. Amino acids, particularly L-glutamate, were also observed in a few extracts, but their concentrations did not increase with salinity. Their presence may have been due to the presence of contaminating bacteria. Results for the freshwater species are summarized in Table 1.

Figure 2(b) shows the spectrum of a typical marine species. In this, as in all other marine species, the spectrum is dominated by resonances from $O$ - $\alpha$-D-glucopyranosyl-( $1 \rightarrow 2)$-glycerol. In a few spectra, resonances were observed from the same glucose-containing polysaccharide as found in the freshwater species, and in some cases amino acids, including L-glutamate, were present, but not as osmoregulatory solutes. A few spectra also contained resonances from low concentrations of glucose and glycerol. This indicated either that these constituents were present at significant concentrations in the live cells prior to harvesting, or that slight decomposition occurred during preparation of the extract, as no changes in the concentrations of glucose and glycerol occurred during spectral acquisition. With the exception of small quantities of glucose derived in this way, no resonances of any other mono- or disaccharides were ever observed in spectra of the marine strains. This does not imply that these constituents were absent from the extract, but indicates that their molar concentrations were so much lower than that of glucosylglycerol as to be undetectable in the spectra. As a corollary, their role in osmoregulation in these species must be insignificant.

The spectrum of a hypersaline species Gloeocapsa N107 (Fig. 2c) contains six resonances from the symmetrical disaccharide trehalose, as well as resonances from the $N$-trimethyl and methylene carbons of glycine betaine, at 54.7 and 67.5 p.p.m., respectively. The resonance from the carboxylate carbon of glycine betaine, near 171 p.p.m., is small because of partial saturation (see above), and therefore it was not used for quantification. The resonances from the $\mathrm{N}$ trimethyl and methylene carbons are split into triplets due to ${ }^{13} \mathrm{C}-{ }^{14} \mathrm{~N}$ coupling (Norton, 1979), but the splittings are not well resolved in Fig. 2(c).

In several spectra a prominent unidentified resonance, near 53.3 p.p.m., was observed. This peak was broad, suggesting that it might arise from carbon coupled to ${ }^{14} \mathrm{~N}$ (as in the case of glycine betaine), but clear splitting was not resolved. The spectrum of a partially purified extract of Calothrix $\mathrm{N} 181$ showed that the solute responsible for this peak also contained two methylene carbons, a methine carbon and two carboxylate carbons, suggesting that this compound may correspond to L-glutamate betaine ( $N$-trimethyl-L-glutamate, compound I).

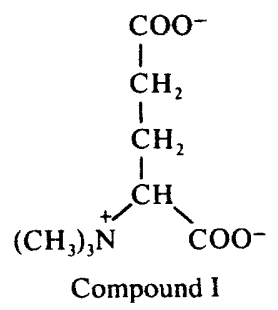

This was confirmed by synthesis of the authentic compound by the method of Dakin \& West (1929). The product had ${ }^{13} \mathrm{C}$ chemical shifts of $25 \cdot 0(\mathrm{t}), 35 \cdot 1(\mathrm{t}), 53 \cdot 5(\mathrm{q}), 80 \cdot 0(\mathrm{~d}), 173 \cdot 2(\mathrm{~s})$ and $181.9(\mathrm{~s})$ in $\mathrm{D}_{2} \mathrm{O}$ at $\mathrm{pH} 9$; and 22.9(t), 31.0(t), 53.6(q), 75.7(d), 170.5(s) and 176.5(s) in $\mathrm{D}_{2} \mathrm{O}$ at $\mathrm{pH} 0.9$, in excellent agreement with those of the osmoregulatory solute found in some of the hypersaline strains. To our knowledge this is the first report of the occurrence of compound $I$ in nature, or of its role in osmoregulation in cyanobacteria. 
Dominant organic osmoregulatory solute:

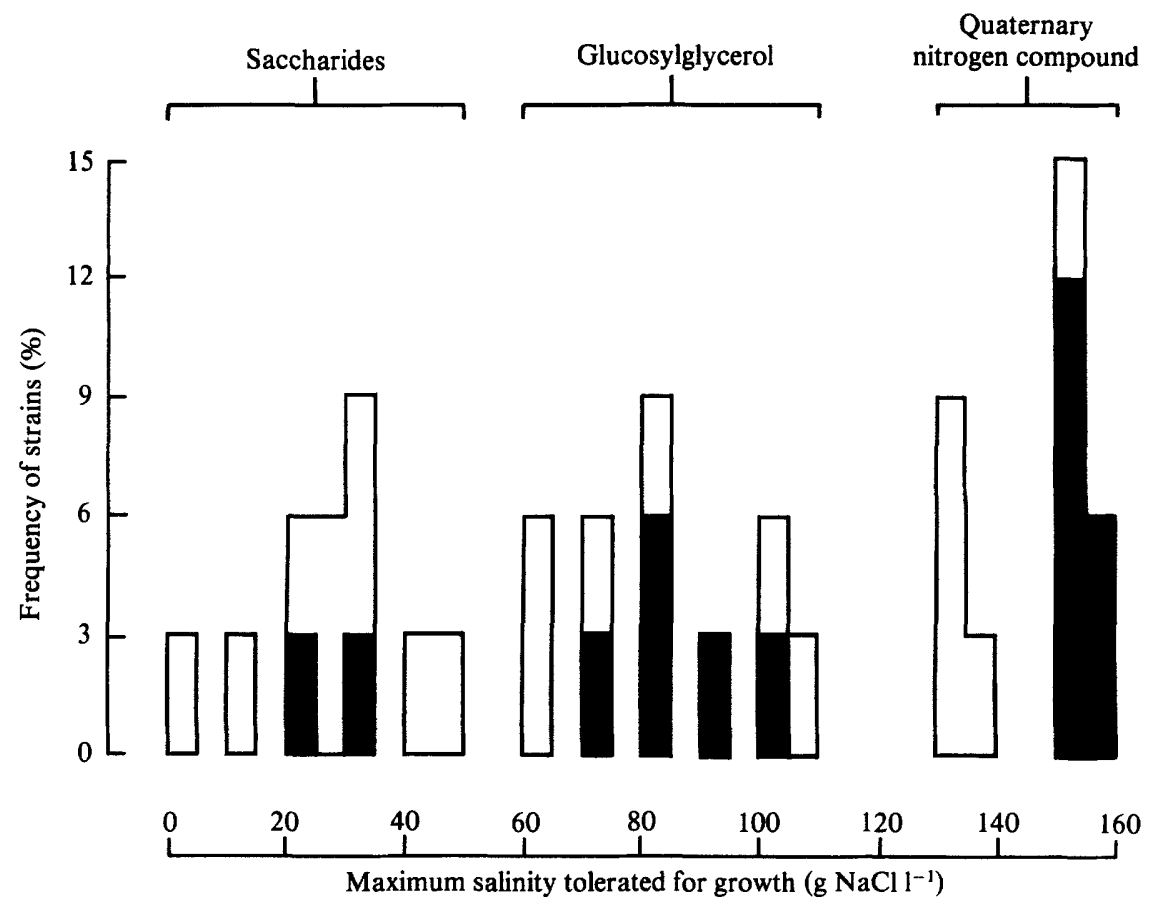

Fig. 3. Distribution of salinity tolerance and dominant organic osmoregulatory solutes in cyanobacteria. Shaded areas represent members of the genus Synechococcus.

In addition to trehalose, glycine betaine and L-glutamate betaine, sucrose was also found in some hypersaline species. Glucosylglycerol was observed in spectra of four species, N163, 352, 355 and 361 , but the levels were always much lower than those of glycine betaine, indicating that it was not the dominant organic osmoregulatory solute in any of these species. L-Glutamate was also present in several extracts, but its concentration did not increase with increasing salinity. The major organic osmoregulatory solutes accumulated by each strain are listed in Table 1, together with the taxonomic assignments and origins of strains.

\section{Habitat}

A good correlation exists between the type of organic solute accumulated and the habitat from which a strain was isolated. Strains accumulating quaternary nitrogen compounds, either with or without disaccharides, were usually isolated from environments in which $\mathrm{NaCl}$ reaches high concentrations, for example the supralittoral zone or salt lakes. Strains in the group which accumulated only saccharides were usually isolated from environments where $\mathrm{NaCl}$ concentrations would be low, such as in lake water or soil. With a few exceptions, strains accumulating glucosylglycerol as their dominant organic osmoregulatory solute were isolated from the marine environment.

Those strains which, although placed in the marine group on the basis of their salt-tolerance range for growth and their accumulation of glucosylglycerol as the dominant osmoregulatory solute, were not directly isolated from a marine source, were isolated from: the Salton Sea (Synechocystis N167), an alkaline pond in Chad (Synechococcus N111), or fresh water (Synechocystis N106). The Salton Sea, in California, is a man-made inland lake which has a salinity and composition similar to that of seawater (Eugster \& Hardie, 1978). We could not obtain from the Pasteur Culture Collection further information on the particular alkaline pond in Chad, which was the source of Synechococcus N111. Waters around Lake Chad range from fresh water $\left(<1 \mathrm{~g}\right.$ dissolved solids $\left.1^{-1}\right)$ to brines dominated by $\mathrm{Na}^{+}-\mathrm{CO}_{3}^{2-}-\mathrm{Cl}^{-}$, with a salinity 
of $300 \mathrm{~g}^{-1}$ at $\mathrm{pH} \mathrm{10.3.} \mathrm{However,} \mathrm{there} \mathrm{are} \mathrm{also} \mathrm{saline} \mathrm{water} \mathrm{bodies} \mathrm{which} \mathrm{do} \mathrm{not} \mathrm{become} \mathrm{very}$ alkaline and in which the dominant ions are $\mathrm{Na}^{+}-\mathrm{Mg}^{2+}-\mathrm{Cl}^{-}-\mathrm{SO}_{4}^{2-}$ (Eugster \& Hardie, 1978), a composition which closely resembles that of seawater.

Synechocystis N106, like Synechocystis PCC 6803, was isolated from fresh water near Berkeley in California (Stanier et al., 1971). Synechocystis PCC 6803 has a salinity tolerance extending to almost $65 \mathrm{~g} \mathrm{NaCl}^{-1}$ and synthesizes glucosylglycerol as the dominant alcohol-soluble low molecular weight organic osmoregulatory solute (Richardson et al., 1983). Both Synechocystis N106 and PCC 6803 will grow in fresh water, like many other marine strains, and so they should be able to survive in a freshwater environment after transfer from the sea by man or other means. Glucosylglycerol was not detected in any other isolates from low salinity environments.

\section{Salinity tolerance groups}

Although there are obviously three groups based on the class of dominant organic solutes accumulated under salt stress, Fig. 1 does not reveal any obvious groups of cyanobacteria with discrete salinity tolerance ranges. However, examination of a frequency histogram of the number of strains versus the maximum salinity tolerated for growth (Fig. 3) reveals that there are three groups of cyanobacteria based on salinity tolerance, and that there is an excellent correlation between the salinity tolerance group and the class of solute accumulated. Contributions of all the Synechococcus strains tested are shaded in Fig. 3 and emphasize the presence of three distinct groups. The three groups are named by describing the most common type of environmental origin of isolates in each group: freshwater, marine and hypersaline.

\section{DISCUSSION}

All cyanobacteria tested showed a positive and measurable response to salinity stress, with organic osmoregulatory solutes being accumulated in every species, regardless of its taxonomic classification, salt tolerance or the habitat from which it was isolated. Cyanobacteria from similar environments accumulated similar major organic osmoregulatory solutes (Table 1). Isolates from fresh water, stream water, lake water or soil accumulated saccharides, while isolates from seawater, the intertidal zone or marine mud produced a heteroside (glucosylglycerol) in response to salt stress. Cyanobacteria from the supralittoral zone, saline pools, hypersaline ponds, salt works and salt lakes predominantly accumulated quaternary nitrogen compounds, such as glycine betaine or L-glutamate betaine. Four strains, N107, N112, N181 and N201, appear to form a further halotolerant subgroup, characterized by accumulation of disaccharides together with quaternary nitrogen compounds.

Previously we proposed that 'marine' cyanobacteria could be identified by their ability to synthesize and accumulate glucosylglycerol as a major osmoregulatory compound and by their related ability to grow in seawater-based medium with total maximum $\mathrm{NaCl}$ of $60-110 \mathrm{~g}^{-1}$ (Mackay et al., 1983). The present results support this proposal, and demonstrate that the correlations of habitat, salinity tolerance and class of major organic osmoregulatory solute accumulated extend to freshwater and hypersaline species. The finding that glucosylglycerol is present in some hypersaline species does not negate this correlation, but emphasizes that it applies to the dominant organic osmoregulatory solutes. Natural-abundance ${ }^{13} \mathrm{C}$ NMR spectroscopy is ideally suited to identifying the dominant organic solute(s) in an extract, as indicated in Results.

The three classes of solutes found as dominant osmoregulatory solutes in cyanobacteria have also been found as dominant osmoregulatory solutes in plants, lichen, algae and phototrophic and heterotrophic bacteria, and there is some correlation between habitat and class of organic osmoregulatory solute found in these organisms too. The most striking correlation is found in organisms from hypersaline environments. In Ectothiorhodospira halochloris, an extremely halophilic, phototrophic bacterium with a salinity optimum of $200 \mathrm{~g} \mathrm{NaCl}^{-1}$, the concentration of glycine betaine increases with increasing salinity and can account for up to $10 \%$ of cell dry weight (Galinski \& Trüper, 1982). In exponential phase cells of the moderately halophilic bacterium $\mathrm{Ba}_{1}$ the intracellular level of glycine betaine is directly proportional to salt-stress at 
salinities of $0.5-3.0 \mathrm{M}-\mathrm{NaCl}$ (Risk et al., 1982). In halophytes (plants able to grow in environments where the $\mathrm{NaCl}$ concentration is subject to wide fluctuations, such as in coastal salt marshes), increased synthesis of glycine betaine in response to salt stress correlates with the salt resistance of the plants (Storey \& Wyn Jones, 1975, 1977).

Heterosides are the major photosynthetic products and low molecular weight storage products of marine red algae (Craigie, 1974). An osmoregulatory role for the heterosides was reported for several species by Kauss (1968), although Kremer (1979) was unable to confirm these results. However, heterosides have undisputed roles as osmoregulatory solutes in some marine and brackish water organisms. Porphyra purpurea accumulates floridoside $(O-\alpha$-D-galactopyranosyl$(1 \rightarrow 2)$-glycerol), Poterioochromonas malhamensis isofloridoside $(O-\alpha$-D-galactopyranosyl- $(1 \rightarrow 1)$ glycerol) and Lichina pygmaea mannosidomannitol (Reed et al., 1980; Kauss, 1967; Feige, 1972). The group of cyanobacteria designated as marine all accumulated the heteroside $O-\alpha-\mathrm{D}$-glucopyranosyl-(1 $\rightarrow 2)$-glycerol (Mackay et al., 1983).

The green algae Scenedesmus obliquus and Chlorella pyrenoidosa accumulate the disaccharide sucrose when salt-stressed (Kauss, 1977). Cyanobacteria isolated from fresh water or soil also accumulate disaccharides (sucrose and/or trehalose).

Osmoregulatory solutes which accumulate to high concentration and in doing so do not inhibit enzyme activity have been termed compatible solutes (Brown \& Simpson, 1972). These compatible solutes are thought to act either by a co-operative binding to proteins which does not induce a conformational change, or by affecting the water domain surrounding the hydrophobic groups in the protein, rather than binding to the protein itself (Borowitzka, 1981). None of the osmoregulatory solutes found among the cyanobacteria has been assayed for their effects on enzyme activity in cell-free cyanobacterial systems, but some have been assayed in other cellfree systems. Monosaccharides and disaccharides are considered poor compatible solutes because high concentrations inhibit enzyme activity (Brown, 1976; Simpson, 1976; Rozema et al., 1978). This may account, at least in part, for the poor salt-tolerance of fresh water cyanobacteria. Glucosylglycerol has not been assayed for its effects on enzyme activity. Glycine betaine is well documented as a good compatible solute. When present at $0.5 \mathrm{M}$ it does not significantly inhibit enzyme activity, mitochondrial or chloroplast function, polysomes or protein synthesis, and may even partly protect some enzymes against salt toxicity (Pollard \& Wyn Jones, 1979; Wyn Jones, 1980).

The data on dominant organic osmoregulatory solute type, strain habitat and salinity tolerance presented here show three broad salt-tolerance groups: freshwater, marine and hypersaline. Rippka et al. (1979) distinguished only between marine and freshwater cyanobacteria, and defined as marine those strains which would not grow in BG-11, even when supplemented with $30 \mathrm{~g} \mathrm{NaCl}^{-1}$, because they had elevated requirements for $\mathrm{Na}^{+}, \mathrm{Cl}^{-}, \mathrm{Mg}^{2+}$ and $\mathrm{Ca}^{2+}$. While the majority of saline water bodies ( $25 \mathrm{~g}$ total dissolved solids $1^{-1}$ ) have $\mathrm{Na}^{+}$ as the major dominant cation and $\mathrm{Cl}^{-}$or $\mathrm{Cl}^{-}$plus $\mathrm{SO}_{4}^{2-}$ as the dominant counter ion(s), the concentrations of other ions can vary dramatically, due to precipitation of mineral salts and exchange reactions with clay minerals (Eugster \& Hardie, 1978). In testing the salinity tolerance of cyanobacteria, we distinguished between the response to the varying ion concentrations and the response to the osmotic stress of the total solute load (mostly due to $\mathrm{NaCl}$ ) by always testing all the cyanobacteria isolated from marine or more saline sources with seawater concentrations of $\mathrm{Mg}^{2+}$ and $\mathrm{Ca}^{2+}$. To examine ionic requirements most strains were also tested for growth in BG-11.

Figure 1 indicates that some cyanobacteria isolated from marine or hypersaline environments did not require high concentrations of $\mathrm{NaCl}$ to support growth even with low concentrations of $\mathrm{Mg}^{2+}$ and $\mathrm{Ca}^{2+}$ (in BG-11), while other strains required low $\left(5.8 \mathrm{~g} \mathrm{l}^{-1}\right)$ to moderate (7.0$21.6 \mathrm{~g} \mathrm{l}^{-1}$ ) concentrations of $\mathrm{NaCl}$, with seawater concentrations of $\mathrm{Mg}^{2+}$ and $\mathrm{Ca}^{2+}$, to support growth. The different minimum ionic requirements displayed by the cyanobacteria we tested are typical of those found in marine (Reichelt \& Baumann, 1974; Gow et al., 1981) and moderately halophilic (Brown, 1976) bacteria, and are consistent with our classification of cyanobacteria based on major organic osmoregulatory solute and salinity tolerance.

There has been debate over the existence of true halophiles among very salt-tolerant 
(hypersaline) strains of cyanobacteria. Hof \& Frémy (1933) considered truly halophilic forms as those able to develop in solutions more concentrated than $3 \mathrm{M}-\mathrm{NaCl}$. Later authors introduced the concepts of a minimum requirement for $\mathrm{NaCl}$ to support growth, optimal growth in solutions more saline than seawater, and the ability to grow in saturated $\mathrm{NaCl}$ (Brock, 1976; Yopp et al., 1978a).

Brown (1976) listed the approximate salt relations of a number of micro-organisms described as non-halophilic, moderately halophilic, halophilic or extremely halophilic. Non-halophilic bacteria have low salt optima, usually in the range $0 \cdot 2-0 \cdot 3 \mathrm{M}-\mathrm{NaCl}$ and do not tolerate more than about $1.5 \mathrm{M}-\mathrm{NaCl}$. Moderate halophiles can be distinguished by their higher salt optimum for growth (near $1.0 \mathrm{M}-\mathrm{NaCl}$ ) and by their extended salinity tolerance (to $4.0 \mathrm{M}-\mathrm{NaCl}$ ). True halophiles have much higher salt optima for growth $(1 \cdot 7-3.8 \mathrm{M}-\mathrm{NaCl})$. Their salinity tolerance is different from that of non-halophiles and moderate halophiles, in that they require a minimum of $1.5-2.0 \mathrm{M}-\mathrm{NaCl}$ to support any growth at all. They are also able to grow in solutions of $5 \mathrm{M}$ to saturated $\mathrm{NaCl}$. Extreme halophiles have salt optima of 3.4-5.0 $\mathrm{M}-\mathrm{NaCl}$, grow well in saturated brine and have a minimum requirement for $2.9 \mathrm{M}-\mathrm{NaCl}$.

Strains of cyanobacteria reported to be halophilic or extremely halotolerant have been isolated by Hof \& Frémy (1933), Kao et al. (1973), Brock (1976), Miller et al. (1976) and Mohammad et al. (1983). The isolates examined by Hof \& Fremy (1933) have upper salt tolerance limits for growth of less than or equal to that of moderate halophiles (Brown, 1976). All the other strains do not have the minimum growth requirement for $1.5-2.0 \mathrm{M}-\mathrm{NaCl}$ characteristic of halophiles and so cannot be defined as truly halophilic. Most of the strains have characteristics which obviously group them with the moderately halophilic bacteria.

The most salt-tolerant cyanobacteria we tested were Synechococcus N161 and 351. On medium solidified with $7 \mathrm{~g}$ Difco Bacto agar $1^{-1}$ at $38-41^{\circ} \mathrm{C}$ and $18-24 \mu \mathrm{E} \mathrm{m}^{-2} \mathrm{~s}^{-1}(1 \cdot 3-$ $1.7 \mathrm{klx})$, these strains had upper salt tolerance limits of $240 \mathrm{~g} \mathrm{NaCl}^{-1}(4.2 \mathrm{M})$ and $210 \mathrm{~g} \mathrm{NaCl}$ $1^{-1}(3.6 \mathrm{M})$, respectively. Both these strains had low growth requirements for $\mathrm{NaCl}$ (about $0.2 \mathrm{M}$ ) and have salinity optima in the range $1.0-1.7 \mathrm{M}-\mathrm{NaCl}$. These strains can therefore be described as moderately halophilic. However, not all cyanobacteria able to grow at or above $130 \mathrm{~g} \mathrm{NaCl}$ $1^{-1}(2 \cdot 2 \mathrm{M})$ can be classified as moderate halophiles, because the level of $\mathrm{NaCl}$ they require for optimal growth and the maximum $\mathrm{NaCl}$ tolerated for growth may be too low. For example, although the maximum salinity that Gloeocapsa N107 and LPP N112 tolerate for growth is 2.2$2.5 \mathrm{M}-\mathrm{NaCl}$, these cyanobacteria have salinity optima in the range $0.2-0.5 \mathrm{M}-\mathrm{NaCl}$. These strains might be better described as halotolerant.

We and others (Hof \& Frémy, 1933; Mohammad et al., 1983) have found that morphological variability can be dramatic among single-cell, moderately halophilic cyanobacteria. Cell shape can change from coccoid to elliptical, to bacilliform and even to filamentous, and the number of planes of division can vary. The nomenclature of the various morphological forms has led to confusion in the taxonomy, because little phenotypic or genotypic data were available. Rippka et al. (1979) used minimum requirements for growth rather than habitat as a reliable phenotypic marker in their taxonomic classification of cyanobacteria. Recently, Richardson et al. (1983) noted the importance of both habitat and salinity tolerance when used as taxonomic characters, and Mohammad et al. (1983) considered the question of whether osmoregulatory solutes were species-specific or habitat-linked.

The genotypic analysis of Synechococcus, as defined by Rippka et al. (1979), suggests that there may be three genera characterized by low, intermediate and high $\mathrm{mol} \% \mathrm{G}+\mathrm{C}$, but data on habitat did not suggest a further classification to species. Data on the $G+C$ content (Rippka et al., 1979) of some of the Synechococcus strains we tested indicate that representatives of the different salinity tolerance groups will probably be found in each of the three $G+C$ groups. For example, Synechococcus N111 (marine) and 7418 (moderately halophilic) occur in the low G + C group, Synechococcus N102 (freshwater) and N166 (marine) are in the intermediate G + C group and Synechococcus N158 (freshwater) is in the high G + C group. There is, however, insufficient genotypic data to suggest that salinity tolerance, class of dominant organic osmoregulatory solute and habitat reflect different species within a particular $\mathrm{G}+\mathrm{C}$ group. 
Most cyanobacteria are notable for their lack of phenotypic traits suitable for numerical analysis, and the results of Rippka et al. (1979) for Synechococcus strains are typical of all cyanobacteria as a group. Most of the strains did not possess the phenotypic abilities or traits examined. For example, most are not facultative photoheterotrophs; they cannot grow using glucose, fructose, sucrose, ribose, glycerol, acetate or glycollate as their sole carbon source. All the Synechococcus strains we examined accumulate some dominant organic osmoregulatory solute(s) and could be clearly recognized as belonging to one of three physiological groups on the basis of either the solute class or the salinity tolerance of the strain. Because all cyanobacteria accumulate some major organic solute(s), this ability to categorize cyanobacteria extends to all taxonomic subdivisions, and the major solutes accumulated may be useful traits in numerical taxonomy of cyanobacteria.

After submission of our manuscript, a paper by Reed et al. (1984) identified three carbohydrates, sucrose, trehalose and glucosylglycerol, as organic osmoregulatory solutes in freshwater and marine species, in agreement with our findings. However, while the trend was towards glucosylglycerol accumulation in marine strains and sucrose and trehalose accumulation in freshwater forms, they found no absolute differences between cyanobacteria isolated from each habitat.

Reed et al. (1984) classified strains as freshwater or marine on the basis of their origin or habitat, and examined the ability of these strains to grow in freshwater or marine media, which property reflects the minimum ionic requirements for growth. By contrast, we examined the salinity tolerance range of each strain, and our classification is based on the maximum salinity tolerated for growth. By this latter criterion, the strains fall into three broad categories, characterized by different profiles of organic osmoregulatory solutes, as shown by the frequency histogram (Fig. 3). These groups were designated freshwater, marine and hypersaline, according to the habitat which typifies each group. Because there are no data in the paper of Reed et al. (1984) on the maximum salinities tolerated for growth of the strains tested, their results do not negate the correlation found in our work between salinity tolerance and class of major organic osmoregulatory solute accumulated.

Reed et al. (1984) did not test for organic osmotica other than carbohydrates. The technique of ${ }^{13}$ C NMR spectroscopy, as used in our work, detects all classes of low molecular weight organic solutes, and provides, therefore, a more comprehensive picture of the solute content of each strain. In particular, we have detected glycine betaine and L-glutamate betaine in several hypersaline strains. Some of these strains also accumulated sucrose and trehalose, which occur in freshwater strains. It is possible that those strains found by Reed et al. (1984) to grow only in marine medium and to accumulate sucrose or trehalose may fall into this category. A screen of carbohydrate content alone does not permit a distinction to be made between the organic osmoregulatory solutes of freshwater strains and those of some hypersaline strains.

\section{REFERENCES}

Batterton, J. C. \& Van BaAlen, C. (1971). Growth responses of blue-green algae to sodium chloride concentration. Archives of Microbiology 76, 151-165.

Blumwald, E. \& Tel-Or, E. (1982). Osmoregulation and cell composition in salt-adaptation of Nostoc muscorum. Archives of Microbiology 132, 168-172.

BorowitzKA, L. J. (1981). Solute accumulation and regulation of cell water activity. In Physiology and Biochemistry of Drought Resistance, pp. 97-130. Edited by L. G. Paleg \& D. Aspinall. New York: Academic Press.

BorowitzKa, L. J., Demmerle, S., MaCkay, M. A. \& Norton, R. S. (1980). Carbon-13 nuclear magnetic resonance study of osmoregulation in a blue-green alga. Science 210, 650-651.

BroCK, T. D. (1976). Halophílic-blue-green algae. Archives of Microbiology 107, 109-111.
Brown, A. D. (1976). Microbial water stress. Bacteriological Reviews 40, 803-846.

Brown, A. D. \& Simpson, J. R. (1972). Water relations of sugar-tolerant yeasts: the role of intracellular polyols. Journal of General Microbiology 72, 589591.

Castenholtz, R. W. (1970). Laboratory culture of thermophilic cyanophytes. Schweizerische Zeitschrift für Hydrologie 32, 538-551.

Craigie, J. S. (1974). Storage Products. In Botanical Monographs Vol. 10, Algal Physiology and Biochemistry, pp. 206-235. Edited by W. D. P. Stewart. Oxford: Blackwell Scientific.

DAKIN, H. D. \& WEST, R. (1929). Note on trimethyl- $\alpha$ glutarobetaine. Journal of Biological Chemistry 83, 773-776.

Eugster, H. P. \& HARdie, L. A. (1978). Saline Lakes. 
In Lakes - Chemistry, Geology, Physics, pp. 237-293. Edited by A. Lerman. New York: Springer-Verlag.

FEIGE, G. B. (1972). Ecophysiological aspects of carbohydrate metabolism in marine blue-green algae lichen Lichina pygmaea $\mathrm{Ag}$. Zeitschrift für Pflanzenphysiologie 68, 12l-126.

Galinski, E. A. \& TrüPer, H. G. (1982). Betaine, a compatible solute in the extremely halophilic phototrophic bacterium Ectothiorhodospira halochloris. FEMS Microbiology Letters 13, 357-360.

GoLUBIC, S. (1980). Halophily and halotolerance in cyanophytes. Origins of Life 10, 169-183.

Gow, J. A., MACLeod, R. A., Goodbody, M., Frank, D. \& DEVoE, L. (1981). Growth characteristics at low $\mathrm{Na}^{+}$concentration and the stability of the $\mathrm{Na}^{+}$requirement of a marine bacterium. Canadian Journal of Microbiology 27, 350-363.

Hocking, A. D. \& Norton, R. S. (1983). Naturalabundance ${ }^{13} \mathrm{C}$ nuclear magnetic resonance studies on the internal solutes of xerophilic fungi. Journal of General Microbiology 129, 2915-2925.

HoF, T. \& FrÉmY, P. (1933). On Myxophyceae living in strong brines. Recueil des travaux botaniques neerlandais 30, 140-161.

KAO, O. H. W., Berns, D. S. \& Town, W. R. (1973). The characterization of C-phycocyanin from an extremely halo-tolerant blue-green alga, Coccochloris elabens. Biochemical Joumal 131, 39-50.

KAUss, H. (1967). Metabolism of isofloridoside ( $O-\alpha-D-$ galactopyranosyl-( $1 \rightarrow 1)$-glycerol) and osmotic balance in the fresh water alga Ochromonas. Nature, London 214, 1129-1130.

KAUSS, H. (1968). $\alpha$-Galactosyl-glyceride und osmoregulation in Rotalgen. Zeitschrift für Pflanzenphysiologie 58, 428-433.

KAUSs, H. (1977). Biochemistry of osmoregulation. In International Review of Biochemistry, vol. 13. Plant Biochemistry II, pp. 119-140. Edited by D. H. Northcote. Baltimore: University Park Press.

KREMER, B. P. (1979). Photoassimilatory products and osmoregulation in marine Rhodophyceae. Zeitschrift für Pflanzenphysiologie 93, 139-147.

MACKaY, M. A., Norton, R. S. \& Borowitzka, L. J. (1983). Marine blue-green algae have a unique osmoregulatory system. Marine Biology 73, 301-307.

Miller, D. M., Jones, J. H., Yopp, J. H., Tindall, D. R. \& SCHMID, W. E. (1976). Ion metabolism in a halophilic blue-green alga, Aphanothece halophytica. Archives of Microbiology 111, 145-149.

Mohammad, F. A. A., Reed, R. H. \& Stewart, W. D. P. (1983). The halophilic cyanobacterium Synechocystis DUN52 and its osmotic responses. FEMS Microbiology Letters 16, 287-290.

NorTON, R. S. (1979). Identification of mollusc metabolites by natural-abundance ${ }^{13} \mathrm{C}$ NMR studies of whole tissue and tissue homogenates. Comparative Biochemistry and Physiology 63B, 67-72.

NORTON, R. S. (1980). ${ }^{13}$ C NMR studies of intact cells and tissue. Bulletin of Magnetic Resonance 3, 29-48.

Norton, R. S., Mackay, M. A. \& Borowitzka, L. J. (1982). The physical state of osmoregulatory solutes in unicellular algae. A natural-abundance carbon-13 nuclear-magnetic-resonance relaxation study. Biochemical Journal 202, 699-706.

Pollard, A. \& Wyn Jones, R. G. (1979). Enzyme activities in concentrated solutions of glycine betaine and other solutes. Planta 144, 291-298.

ReEd, R. H., Collins, J. C. \& Russell, G. (1980). The effects of salinity upon galactosylglycerol content and concentration of the marine red alga Porphyra purpurea (Roth.) C. Ag. Journal of Experimental Botany 31, 1539-1554.

ReED, R. H., Richardson, D. L., WARR, S. R. C. \& Stewart, W. D. P. (1984). Carbohydrate accumulation and osmotic stress in cyanobacteria. Journal of General Microbiology 130, 1-4.

Reichelt, J. L. \& BaumanN, P. (1974). Effect of sodium chloride on growth of heterotrophic marine bacteria. Archives of Microbiology 97, 329-345.

Richardson, D. L., ReEd, R. H. \& Stewart, W. D. P. (1983). Synechocystis PCC 6803: a euryhaline cyanobacterium. FEMS Microbiology Letters 18, 99 102.

RiPPKA, R., Deruelles, J., WATERbuRY, J. B., Herdman, M. \& Stanier, R. Y. (1979). Generic assignments, strain histories and properties of pure cultures of cyanobacteria. Joumal of General Microbiology 111, 1-61.

Risk, M., Gelber, R., KNOCK, S. \& WoOd, R. C. (1982). Osmoregulatory mechanisms of the mesohalophilic Dead Sea bacterium $\mathrm{Ba}_{1}$. In Biosaline Research: a Look to the Future, pp. 539-544. Edited by A. San Pietro. New York: Plenum Press.

Rosenthal, S. N. \& Fendler, J. H. (1976). ${ }^{13}$ C NMR spectroscopy in macromolecular systems of biochemical interest. Advances in Physical Organic Chemistry 13, 279-424.

Rozema, J., Buizer, D. A. G. \& FABritus, H. E. (1978). Population dynamics of Glaux maritima and ecophysiological adaptations to salinity and inundation. Oikos 30, 539-548.

Simpson, J. R. (1976). Water relations of the sugartolerant yeast, Saccharomyces rouxii. PhD thesis, University of New South Wales, Australia.

Stam, W. T. \& Holleman, H. C. (1975). The influence of different salinities on growth and morphological variability of a number of Phormidium strains (Cyanophyceae) in culture. Acta botanica neerlandica 24, 379-390.

Stam, W. T. \& Holleman, H. C. (1979). Cultures of Phormidium, Plectonema, Lyngbya and Synechococcus (Cyanophyceae) under different conditions : their growth and morphological variability. Acta botanica neerlandica $28,45-66$.

Stanier, R. Y., KunisAWA, R., MANDEL, M. \& CohenBazire, G. (1971). Purification and properties of unicellular blue-green algae (order Chroococcales). Bacteriological Reviews 35, 171-205.

StewarT, W. D. P. (1964). Nitrogen fixation by Myxophyceae from marine environments. Journal of General Microbiology 36, 415-422.

STOREY, R. \& WYN JONES, R. G. (1975). Betaine and choline levels in plants and their relationship to $\mathrm{NaCl}$ stress. Plant Science Letters 4, 161-168.

StOREY, R. \& WYN JoNes, R. G. (1977). Quaternary ammonium compounds in plants in relation to salt resistance. Phytochemistry 16, 447-453.

VAN BAALEN, C. (1962). Studies on marine blue-green algae. Botanica marina 4, 129-139.

W ATERbury, J. B. \& Stanier, R. Y. (1978). Patterns of 
growth and development in pleurocapsalean cyanobacteria. Microbiological Reviews 42, 2-44.

WYN JONES, R. G. (1980). An assessment of quaternary ammonium and related compounds as osmotic effectors in crop plants. In Basic Life Sciences, vol. 14, Genetic Engineering of Osmoregulation: Impact on Plant Productivity for Food, Chemicals and Energy, pp. 155-170. Edited by D. W. Rains, R. C. Valentine \& A. Hollaender. New York: Plenum Press.

Yopp, J. H., Tindall, D. R., Miller, D. M. \& SCHMID, W. E. (1978a). Isolation, purification and evidence for a halophilic nature of the blue-green alga Aphanothece halophytica Frémy (Chroococcales). Phycologia 17, 172-178.

YOPP, J. H., MilleR, D. M. \& TINDALl, D. R. (1978b). Regulation of intracellular water potential in the halophilic blue-green alga Aphanothece halophytica (Chroococcales). In Energetics and Structure of Halophilic Microorganisms, pp. 619-624. Edited by S. R. Caplan \& M. Ginzburg. Amsterdam: Elsevier/ North Holland.

ZoBell, C. (1963). Domain of the marine microbiologist. In Symposium on Marine Microbiology, pp. 324. Edited by C. H. Oppenheimer. Springfield, Illinois: Charles C. Thomas. 